\title{
Prevention of type 1 diabetes by gene therapy
}

\author{
Chaorui Tian, ${ }^{1}$ Jessamyn Bagley, ${ }^{1}$ Nathalie Cretin, ${ }^{1}$ Nilufer Seth, ${ }^{2}$ \\ Kai W. Wucherpfennig, ${ }^{2}$ and John lacomini ${ }^{1}$
}

\author{
${ }^{1}$ Massachusetts General Hospital and Harvard Medical School, Boston, Massachusetts, USA. ${ }^{2}$ Department of Cancer Immunology and AIDS, \\ Dana-Farber Cancer Institute, Boston, Massachusetts, USA.
}

\begin{abstract}
The autoimmune disease type 1 diabetes in humans and NOD mice is determined by multiple genetic factors, among the strongest of which is the inheritance of diabetes-permissive MHC class II alleles associated with susceptibility to disease. Here we examined whether expression of MHC class II alleles associated with resistance to disease could be used to prevent the occurrence of diabetes. Expression of diabetes-resistant MHC class II I-A $\beta$ chain molecules in NOD mice following retroviral transduction of autologous bone marrow hematopoietic stem cells prevented the development of autoreactive $T$ cells by intrathymic deletion and protected the mice from the development of insulitis and diabetes. These data suggest that type 1 diabetes could be prevented in individuals expressing MHC alleles associated with susceptibility to disease by restoration of protective MHC class II expression through genetic engineering of hematopoietic stem cells.
\end{abstract}

\section{Introduction}

Type 1 diabetes is caused by $\mathrm{T}$ cell-mediated autoimmune destruction of insulin-producing $\beta$ cells in the pancreas. Multiple genes contribute to the development of type 1 diabetes; however, the inheritance of MHC alleles associated with susceptibility to disease (at-risk alleles) that lack a charged amino acid at position 57 of the MHC class II $\beta$ chain is a principal determining genetic component in humans (1-4). Conversely, inheritance of MHC class II alleles containing a charged amino acid at position 57 of the $\beta$ chain is associated with protection from disease. In some populations, as many as $28 \%$ of individuals that inherit particular HLA-DQ alleles such as DQB1*0302 and 34\% that inherit DQB1*0201 develop diabetes (5). The MHC class II region in NOD mice, a model of spontaneous type 1 diabetes (6), encodes a single MHC class II molecule, I-Ag7 (the mouse homologue of HLA-DQB1), which contains polymorphisms that are strikingly similar to those in human alleles associated with type 1 diabetes susceptibility (7).

At-risk alleles in humans and NOD mice are structurally distinct from diabetes-resistant alleles, and in both cases the lack of a charged amino acid at position 57 of the $\beta$ chain prevents the formation of a salt bridge with an arginine 76 of the $\alpha$ chain. This polymorphism leads to structural abnormalities that result in aberrant peptide binding and presentation (8) and has been suggested to affect the ability of these molecules to effectively mediate efficient negative selection of autoreactive $T$ cells during their development (9-14). Alternatively, structural abnormalities present in at-risk alleles could contribute to diabetes development by failing to positively select $\mathrm{T}$ cells that can control disease (15).

Transgenic NOD mice that express MHC class II genes other than I-Ag7 do not develop diabetes (16-23). Transplantation of allogeneic bone marrow from strains that do not spontaneously develop diabetes also prevents the occurrence of diabetes in NOD mice (24-28). While these studies support the idea that MHC plays a major role in the development of type 1 diabetes, the mechanism by which diabetes-resistant MHC alleles prevent disease is unknown. In transgenic

Nonstandard abbreviations used: GAD 65, glutamic acid decarboxylase 65; MBP, myelin basic protein; PE, phycoerythrin.

Conflict of interest: The authors have declared that no conflict of interest exists.

Citation for this article: J. Clin. Invest. 114:969-978 (2004).

doi:10.1172/JCI200422103. mice, diabetes-resistant MHC class II molecules are expressed on both thymic epithelium and bone marrow-derived cells. Therefore, protection from diabetes could occur by positive selection of regulatory $\mathrm{T}$ cells or negative selection of self-reactive $\mathrm{T}$ cells. In bone marrow chimeras, diabetes-resistant MHC class II molecules are expressed only on hematopoietic cells. However, allogeneic bone marrow cells also express non-MHC-encoded genes that influence diabetes progression in NOD mice (29). Therefore, from these studies, it is impossible to determine the mechanism of the protection and whether expression of diabetes-resistant MHC on bone marrow-derived cells alone is sufficient to prevent diabetes.

We hypothesized that if expression of diabetes-resistant MHC class II alleles on bone marrow-derived cells is sufficient to prevent diabetes, genetic engineering of autologous hematopoietic stem cells could be used to restore expression of diabetes-resistant MHC on bone marrow-derived cells. Furthermore, expression of diabetes-resistant MHC class II alleles on bone marrow-derived cells could mediate negative selection of self-reactive $\mathrm{T}$ cells that cause diabetes, thereby preventing disease. This approach could have significant advantages over transplantation of allogeneic bone marrow cells, because the possibility of graft-versus-host disease would be avoided. Here we show that expression of diabetes-resistant MHC class II I-A $\beta$ chain molecules on hematopoietic cells following retroviral transduction of bone marrow is sufficient to prevent the occurrence of type 1 diabetes in NOD mice. Our data demonstrate that expression of diabetes-resistant MHC class II molecules on hematopoietic cells leads to negative selection of self-reactive diabetogenic $T$ cells, thereby preventing insulitis and destruction of $\beta$ cells in the pancreas. Furthermore, these data suggest that genetic engineering of autologous hematopoietic stem cells could be used to prevent diabetes occurrence in high-risk individuals who inherit diabetes-permissive MHC class II alleles.

\section{Results}

Construction and characterization of retroviruses carrying MHC class IIGFP fusion genes. To examine the role of MHC class II in providing protection from diabetes, genetic engineering of bone marrow was used to achieve expression of diabetes-resistant MHC class II molecules on autologous hematopoietic cells of NOD mice. We reasoned that expression of diabetes-resistant MHC class II $\beta$ chain genes in NOD hematopoietic cells would reconstitute expression of diabe- 


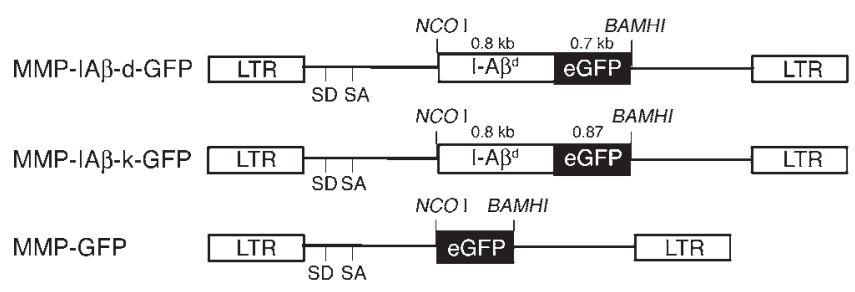

Figure 1

Diagram of MMP-based retroviral vectors encoding I-A $\beta^{\mathrm{d}}$ (MMP-IA $\beta$-dGFP) and I-A $\beta^{k}$ (MMP-IA $\beta$-k-GFP) fused to GFP; and diagram of the control MMP-GFP retroviral vector. LTR, long-terminal repeat.

tes-resistant MHC class II molecules by pairing with endogenous I-A $\alpha$ chains, which are structurally normal. Constructs were prepared in which the cytoplasmic tails of I-A $\beta$ chains from the $H-2^{d}$ and $H-2^{k}$ haplotypes were fused to enhanced GFP to facilitate tracking of diabetes-resistant MHC class II chains in hematopoietic cells. I-A $\beta$ chain-GFP fusion genes were then cloned into the pMMP retroviral vector (Figure 1), and vesicular stomatitis virus G-enveloped retroviruses were prepared from each construct, hereafter referred to as MMP-IA $\beta$-d-GFP and MMP-IA $\beta$-k-GFP virus.

Infection of I-A $\beta$ chain-deficient, surface MHC class II-negative, M12.C3 cells (30) with either MMP-IA $\beta$-d-GFP or MMP-IA $\beta-k-G F P$ virus restored expression of MHC class II on the cell surface (Figure $2 \mathrm{~A})$, indicating that the retrovirally encoded I-A $\beta$ chains were produced and were able to pair with endogenously encoded $\alpha$ chains. To determine whether retrovirally transduced I-A $\beta$ chains could compete with endogenous MHC class II and be expressed on the cell surface, A20 cells ( $H-2^{d}$ positive, BALB/c origin) were infected with MMP-IA $\beta$-k-GFP. Cell surface expression of I-A $\beta^{k}$ was detectable on these infected cells by cell surface staining with the I-A $\beta^{\mathrm{k}}$ chain-reactive antibody 10-3.6 (Figure 2B). In all cases, GFP and I-A $\beta^{\mathrm{k}}$ were con- cordantly expressed. The levels of endogenous I-A expression were unchanged in A20 cells infected with MMP-IA $\beta$-k-GFP virus (Figure $2 \mathrm{~B}$ ), suggesting that the retrovirally encoded I-A $\beta^{\mathrm{k}}$ molecules and the endogenous I-A $\beta^{\mathrm{d}}$ chains are coexpressed on the cell surface.

Long-term expression of retrovirally encoded MHC class II-GFP fusion genes following reconstitution of NOD mice with transduced syngeneic bone marrow. We next examined the ability of MMP-IA $\beta$-d-GFP and MMP-IA $\beta$-k-GFP viruses to transfer I-A $\beta$ chain gene expression to primary murine bone marrow cells. Bone marrow was harvested from female NOD/MrkTac mice (hereafter referred to as NOD mice) treated 7 days prior with $150 \mathrm{mg} / \mathrm{kg} 5$-fluoroura$\mathrm{cil}$, and transduced as previously described (31). Immediately after transduction, approximately $17.2 \% \pm 2.3 \%$ of MMP-IA $\beta$-d-GFPtransduced and $14.4 \% \pm 2.1 \%$ of MMP-IA $\beta$-k-GFP-transduced bone marrow cells expressed GFP (Figure 3A). The frequency of bone marrow cells expressing GFP following infection with either MMP-IA $\beta$-d-GFP or MMP-IA $\beta$-k-GFP was similar to that observed following infection with MMP-GFP $(16.3 \% \pm 1.8 \%)$, a control virus that carries only the gene encoding GFP. Mock-transduced bone marrow cells remained negative (Figure $3 \mathrm{~A}$ ).

To examine expression of retrovirally transduced I-A $\beta$ chain genes in vivo, female NOD mice were lethally irradiated (10.25 Gy) and reconstituted with $4 \times 10^{6}$ MMP-IA $\beta$-d-GFP virus-, MMPIA $\beta$-k-GFP virus-, or MMP-GFP virus-transduced syngeneic bone marrow cells. Eight weeks after bone marrow transplantation, $8.0 \% \pm 0.4 \%(n=18)$ of PBMCs from mice reconstituted with MMP-IA $\beta$-d-GFP-transduced bone marrow expressed GFP. Similarly, $5.0 \% \pm 0.7 \%(n=18)$ of PBMCs from mice reconstituted with MMP-IA $\beta$-k-GFP-transduced bone marrow and $10.6 \% \pm 0.6 \%$ $(n=18)$ of PBMCs from mice reconstituted with control MMPGFP-transduced bone marrow expressed GFP. The frequency of cells expressing GFP remained stable in all mice over the 36-week follow-up period (Figure 3B). Twenty weeks after reconstitu-
A

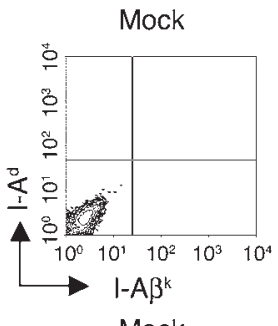

B

A20

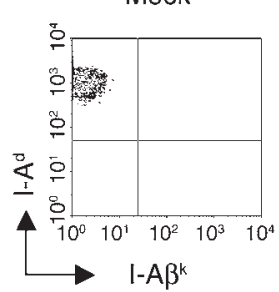

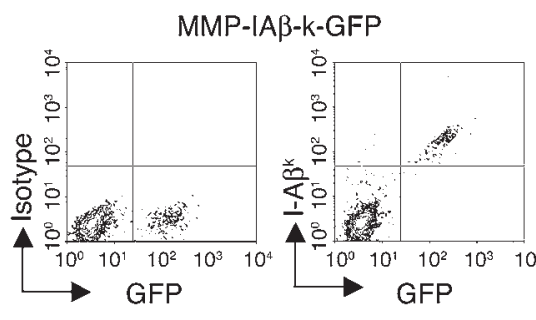

MMP-IA $\beta$-k-GFP
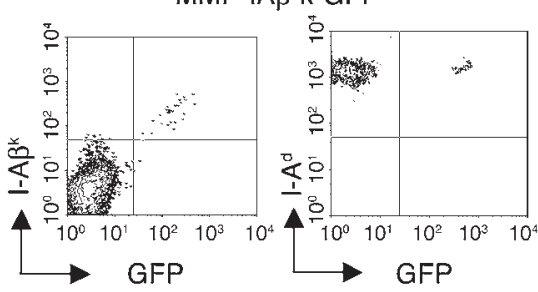

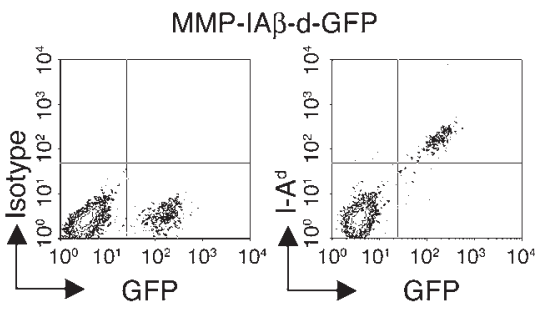

GFP

\section{Figure 2}

Expression of retrovirally transduced MHC class II-GFP fusion proteins. (A) MMP-IA $\beta$-d-GFP and MMP-IA $\beta$-k-GFP retroviruses restore surface expression of MHC class II in I-A $\beta$ chain-deficient M12.C3 cells. M12.C3 cells were cultured with media alone (mock) or infected with cell-free MMP-IA $\beta$-k-GFP or MMP-IA $\beta$-d-GFP retroviral supernatants for 3 days. Cells were harvested, and surface expression of MHC class II was analyzed by staining with anti-MHC mAb's followed by flow cytometry. Shown is 1 representative example of 3 independent experiments. (B) I-A $\beta$ chains encoded by MMP-IA $\beta$-k-GFP are expressed on the surface of cells that express endogenous MHC class II. A20 cells $\left(H-2^{d}\right)$ were cultured with either media alone (mock) or cell-free MMP-IA $\beta$-k-GFP viral supernatant for 3 days. Cells were harvested, and surface expression of MHC class II was analyzed by surface staining with anti-I-A $\beta^{\mathrm{k}}(10-3.6)$ and anti-I-A $\beta^{\mathrm{d}}(39-10-8)$ antibodies followed by flow cytometry. Shown is 1 representative example of 3 independent experiments. 


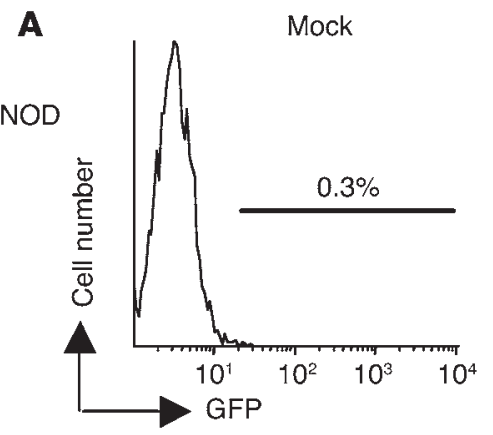

B

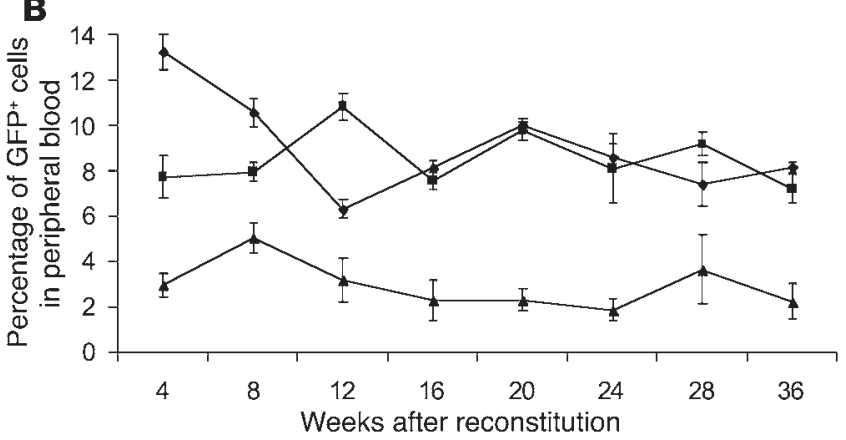

MMP-GFP

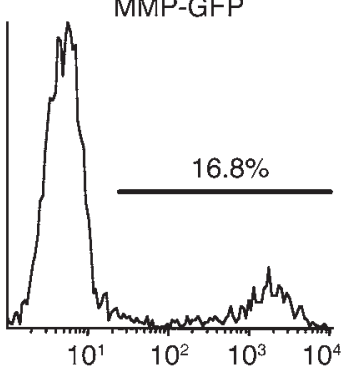

$\mathbf{C}$

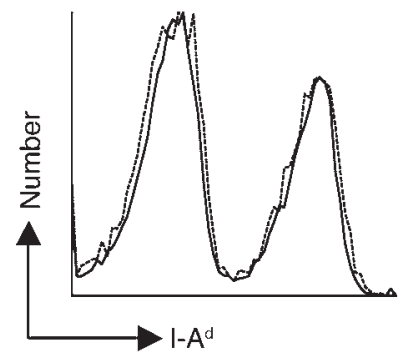

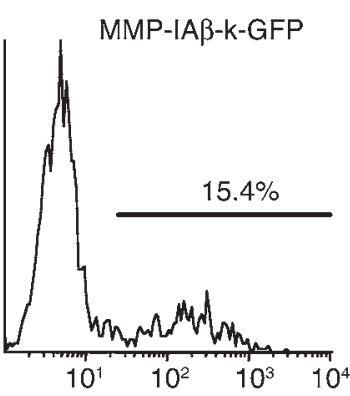

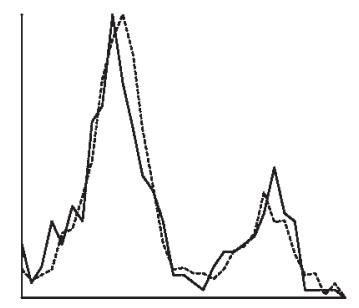

Figure 3

Expression of retrovirally transduced MHC class II $\beta$ chains in vivo. (A) MMP-IA $\beta$-d-GFP and MMP-IA $\beta$-k-GFP viruses effectively infect primary bone marrow cells. Bone marrow cells were harvested from 5 -fluorouracil-treated NOD mice and transduced as described. Immediately after transduction, bone marrow cells were harvested and examined for GFP expression by flow cytometry. One representative experiment of 5 independent experiments is shown. (B) Expression of retrovirally transduced I-A $\beta$ chains is stable. Expression of GFP in PBMCs of NOD mice reconstituted with MMP-IA $\beta$-d-GFP-transduced (squares), MMP-IA $\beta$-k-GFP-transduced (triangles), or control MMP-GFP-transduced bone marrow (diamonds), determined by flow cytometry. Shown are the mean values obtained for 5-6 mice per time point. The data are representative of 3 independent experiments. (C) MHC class II expression levels on the surface of PBMCs. Twenty weeks after bone marrow transplantation, PBMCs were harvested from mice reconstituted with bone marrow transduced with either MMP-IA $\beta$-k-GFP (solid line) or control MMP-GFP virus (dashed line). Cells were stained with anti-I-Ad antibody 39-10-8, which recognizes all cell surface MHC class II, and analyzed by flow cytometry. Left panel: Total cells. Right panel: GFP+ transduced cells.

tion, GFP expression was detected in $\mathrm{CD}^{+} \mathrm{T}$ cells, B220 $\mathrm{B}$ cells, $\mathrm{CD}_{11 \mathrm{~b}^{+}}$macrophages, and CD11 $\mathrm{c}^{+}$dendritic cells in the spleen, PBMCs, bone marrow, and thymus (Table 1).

We next examined whether expression of retrovirally encoded I-A $\beta$ chain affected expression levels of MHC class II. Twenty weeks after bone marrow transplantation, PBMCs were harvested from mice reconstituted with bone marrow transduced with either MMP-IA $\beta$ $\mathrm{k}-\mathrm{GFP}$ or control MMP-GFP virus. Cells were stained with anti-I-A antibody 39-10-8, which recognizes both the endogenous and the retrovirally encoded $\mathrm{MHC}$ class II heterodimers, and analyzed by flow cytometry (Figure 3C). The level of MHC class II expression on PBMCs infected with MMP-IA $\beta$-k-GFP virus was identical to the level on cells infected with control virus. Since total MHC class II levels are unchanged in cells infected with MMP-IA $\beta$-k-GFP virus, and the retrovirally encoded MHC class II $\beta$ chains must compete with $\mathrm{I}-\mathrm{A}^{\mathrm{g} 7} \beta$ chains for endogenously encoded $\alpha$ chain to reach the cell surface, we assume that the total number of $\mathrm{I}-\mathrm{A}^{\mathrm{g}}{ }^{7}$ molecules on cells expressing retrovirally encoded MHC class II $\beta$ chains is reduced.

Retrovirally encoded MHC class II-GFP fusion proteins reach the cell surface only in MHC class II-committed cells. To examine cellular distribution of retrovirally transduced MHC class II $\beta$ chains, confocal microscopy was used to analyze the cellular localization of GFP. PBMCs from NOD mice reconstituted with MMP-IA $\beta$-d-GFP-, MMP-IA $\beta$-k-GFP-, or control MMP-GFP-transduced bone marrow were collected, fixed, and double-stained with the anti-I-A ${ }^{\mathrm{d}}$ antibody 39-10-8 (which cross-reacts with I-Ag7) and the anti-GFP antibody JL-8. Analysis of MHC class II-positive cells in blood revealed that expression of GFP was localized in the cytoplasm of cells from mice reconstituted with MMP-GFP-transduced bone marrow and did not colocalize with endogenous MHC class II on the cell surface (Figure 4A). In contrast, in mice reconstituted with MMP-IA $\beta$-d-GFP-transduced or MMP-IA $\beta$-k-GFP-transduced (not shown) bone marrow, GFP expression was colocalized together with MHC class II on the cell surface (Figure 4A). Thus, in MHC class II-expressing cells, retrovirally encoded I-A $\beta$ chains are processed and exported to the cell surface. Analysis of T cells from mice reconstituted with MMP-IA $\beta$-d-GFP-transduced or MMP-IA $\beta$-k-GFP-transduced (not shown) bone marrow by confocal microscopy revealed expression of GFP within the cytoplasm (Figure 4B). GFP expression in T cells did not colocalize with CD3 on the cell surface (Figure 4B). These data suggest that retrovirally transduced MHC class II $\beta$ chains are expressed in the cytoplasm of MHC class II-negative cells and do not reach the cell surface.

Expression of retrovirally encoded MHC class II-GFP fusion genes in NOD mouse bone marrow-derived cells prevents type 1 diabetes. To determine the effect of expressing retrovirally transduced diabetes-resistant MHC class II genes in bone marrow-derived cells on diabetes occurrence, 5 - to 6-week-old female NOD mice were irradiated and reconstituted with $4 \times 10^{6}$ syngeneic bone marrow cells transduced with MMP-IA $\beta$-d-GFP, MMP-IA $\beta$-k-GFP, or control MMP-GFP 
Table 1

Lineage distribution of GFP-expressing cells in reconstituted mice

\begin{tabular}{|c|c|c|c|c|c|c|c|c|c|}
\hline & & \multicolumn{2}{|c|}{ Spleen } & \multicolumn{2}{|c|}{ PBMCs } & \multicolumn{2}{|c|}{ BM } & \multicolumn{2}{|c|}{ Thymus } \\
\hline & & $\% \operatorname{Lin}^{+A}$ & $\%$ GFP+B & $\% \operatorname{Lin}^{+}$ & $\%$ GFP+ & $\% \operatorname{Lin}^{+}$ & $\%$ GFP+ & $\% \operatorname{Lin}^{+}$ & $\%$ GFP+ \\
\hline \multirow[t]{5}{*}{ MMP-GFP } & TotalC & $9.1 \pm 3.1$ & N/A & $9.7 \pm 3.5$ & N/A & $7.1 \pm 2.9$ & $\mathrm{~N} / \mathrm{A}$ & $3.2 \pm 1.8$ & N/A \\
\hline & Mac-1 & $12.1 \pm 4.3$ & $13.3 \pm 4.6$ & $10.4 \pm 3.7$ & $18.5 \pm 7.2$ & $6.9 \pm 3.2$ & $71.2 \pm 21.3$ & $3.4 \pm 1.2$ & $12.3 \pm 9.5$ \\
\hline & B220 & $8.4 \pm 2.8$ & $65.5 \pm 11.2$ & $8.2 \pm 4.1$ & $52.4 \pm 21.5$ & $9.3 \pm 4.4$ & $33.1 \pm 10.2$ & $2.6 \pm 1.9$ & $37.7 \pm 1.3$ \\
\hline & CD3 & $5.4 \pm 1.1$ & $26.5 \pm 8.6$ & $6.9 \pm 2.6$ & $32.2 \pm 10.2$ & $6.3 \pm 4.1$ & $7.3 \pm 2.1$ & $3.5 \pm 2.6$ & $42.6 \pm 20.4$ \\
\hline & CD11c & $13.5 \pm 8.4$ & $4.1 \pm 0.9$ & $14.6 \pm 6.4$ & $1.2 \pm 0.8$ & $18.3 \pm 8.5$ & $8.5 \pm 4.2$ & $10.9 \pm 8.7$ & $2.9 \pm 2.1$ \\
\hline \multirow[t]{5}{*}{ MMP-IA $\beta$-d-GFP } & Totalc & $8.5 \pm 2.2$ & N/A & $8.9 \pm 2.6$ & N/A & $6.8 \pm 1.4$ & $\mathrm{~N} / \mathrm{A}$ & $2.3 \pm 1.4$ & N/A \\
\hline & Mac-1 & $10.3 \pm 3.2$ & $15.3 \pm 7.2$ & $9.4 \pm 3.1$ & $10.1 \pm 4.3$ & $6.7 \pm 2.2$ & $75.4 \pm 19.4$ & $2.9 \pm 1.6$ & $15.9 \pm 4.9$ \\
\hline & B220 & $12.4 \pm 2.8$ & $73.3 \pm 16.2$ & $11.2 \pm 3.4$ & $49.8 \pm 32.1$ & $29.4 \pm 10.1$ & $26.4 \pm 11.6$ & $4.6 \pm 3.4$ & $49.3 \pm 20.3$ \\
\hline & CD3 & $6.3 \pm 3.7$ & $24.3 \pm 27.4$ & $3.2 \pm 1.2$ & $41.3 \pm 19.4$ & $5.3 \pm 2.8$ & $15.3 \pm 9.2$ & $1.8 \pm 1.3$ & $29.4 \pm 10.5$ \\
\hline & CD11c & $15.4 \pm 8.4$ & $4.2 \pm 1.4$ & $16.5 \pm 10.4$ & $4.3 \pm 2.2$ & $28.4 \pm 13.8$ & $13.3 \pm 5.9$ & $13.1 \pm 9.4$ & $5.3 \pm 4.1$ \\
\hline \multirow[t]{5}{*}{ MMP-IA $\beta$-k-GFP } & Totalc & $4.3 \pm 1.1$ & $\mathrm{~N} / \mathrm{A}$ & $4.8 \pm 1.5$ & $\mathrm{~N} / \mathrm{A}$ & $4.1 \pm 0.8$ & $\mathrm{~N} / \mathrm{A}$ & $1.8 \pm 1.2$ & N/A \\
\hline & Mac-1 & $6.2 \pm 3.4$ & $13.5 \pm 6.4$ & $5.3 \pm 2.8$ & $25.3 \pm 9.4$ & $4.3 \pm 1.2$ & $74.2 \pm 12.9$ & $2.3 \pm 2.1$ & $17.6 \pm 8.9$ \\
\hline & B220 & $4.8 \pm 3.2$ & $67.5 \pm 22.5$ & $7.3 \pm 3.1$ & $71.4 \pm 14.2$ & $26.4 \pm 11.8$ & $22.2 \pm 10.3$ & $4.3 \pm 3.8$ & $42.5 \pm 30.1$ \\
\hline & CD3 & $3.3 \pm 2.4$ & $26.3 \pm 10.2$ & $2.1 \pm 0.7$ & $47.3 \pm 11.7$ & $3.3 \pm 2.9$ & $19.1 \pm 3.5$ & $1.5 \pm 1.1$ & $28.5 \pm 20.1$ \\
\hline & CD11c & $6.7 \pm 5.6$ & $4.2 \pm 2.1$ & $8.3 \pm 5.8$ & $6.1 \pm 2.3$ & $22.4 \pm 13.1$ & $11.3 \pm 2.3$ & $17.3 \pm 6.8$ & $4.2 \pm 3.2$ \\
\hline
\end{tabular}

N/A, not applicable. APercentage of lineage marker-positive cells that express GFP. BPercentage of GFP+ cells expressing each lineage marker. ${ }^{\mathrm{C}}$ Total percentage of GFP+ cells in each tissue. BM, bone marrow; Lin, lineage marker.

virus. Blood glucose levels were then monitored on a weekly basis. Four of six mice reconstituted with MMP-GFP-transduced bone marrow became diabetic by 22 weeks after bone marrow transplantation and were sacrificed (median time of onset, 18 weeks; Figure 5A). In contrast, mice reconstituted with either MMP-IA $\beta$ d-GFP-transduced $(n=6)$ or MMP-IA $\beta$-k-GFP-transduced $(n=6)$ bone marrow were protected from diabetes. These mice remained normoglycemic for 40 weeks after reconstitution $(P<0.01$, median time of onset $>40$ weeks after reconstitution, $n=12)$. All mice remained in good health for the duration of the experiment, and no leukemias or lymphomas were detected (not shown).

Treatment with cyclophosphamide accelerates the occurrence of diabetes in NOD mice and can induce diabetes in mice in which spontaneous hyperglycemia does not develop (32), suggesting that resistance to cyclophosphamide-induced diabetes is a rigorous test of the ability of gene therapy to prevent diabetes in NOD mice. To test the ability of retroviral gene therapy to protect mice from cyclophosphamide-induced diabetes, female NOD mice were reconstituted with MMP-IA $\beta$-d-GFP-, MMP-IA $\beta$-k-GFP-, or

\section{Figure 4}

Subcellular localization of retrovirally encoded I-A $\beta$ chains. (A) Retrovirally encoded I-A $\beta$ chains are expressed on the surface of MHC class II-positive cells. PBMCs were harvested from NOD mice reconstituted with either MMP-GFP-transduced (top panels) or MMP-IA $\beta$-d-GFP-transduced bone marrow (bottom panels), fixed, and stained with antibodies specific for GFP (left panels, green) and $I-A^{d}$ (middle panels, red). The anti-I-A $A^{d}$ antibody used cross-reacts with I-Ag7. Right panels: Overlay images showing colocalization of retrovirally encoded I-A ${ }^{\mathrm{d}}$-GFP fusion proteins with endogenous $\mathrm{I}-\mathrm{A}^{\mathrm{g} 7}$ on the surface in yellow. (B) Retrovirally encoded I-A $\beta$ chains are expressed in the cytoplasm of surface-MHC class II negative cells. PBMCs from NOD mice reconstituted with MMP-IA $\beta$-d-GFP-transduced bone marrow were fixed and stained with antibodies specific for GFP (left panel, green) and anti-CD3 (middle panel, red). An overlay of the 2 images is shown in the right panel, demonstrating that I-A $\beta^{\mathrm{d}}$-GFP does not colocalize with $\mathrm{CD} 3$ on the cell surface of MHC class II-negative cells. Shown are representative results of 3 independent experiments. control MMP-GFP-transduced bone marrow as described above, and, 21 weeks after reconstitution, mice in each group were treated with $200 \mathrm{mg} / \mathrm{kg}$ cyclophosphamide. In these experiments, recipient mice also received anti-CD4 and anti-CD8 antibodies at the time of bone marrow transplantation to deplete any preexisting mature diabetogenic T cells. Treatment of mice with anti-T cell antibodies delays $\mathrm{T}$ cell recovery after bone marrow transplantation and therefore delays the onset of diabetes (J. Iacomini, unpublished observation). Seventy-nine percent of NOD mice (11 of 14) reconstituted with MMP-GFP-transduced bone marrow developed diabetes by 28 weeks after reconstitution and were sacrificed (median time of onset, 23 weeks after reconstitution; Figure 5B).

\section{A}

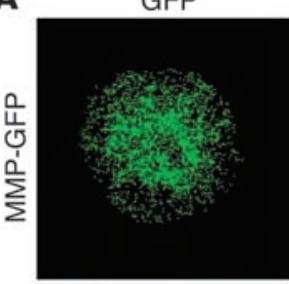

GFP
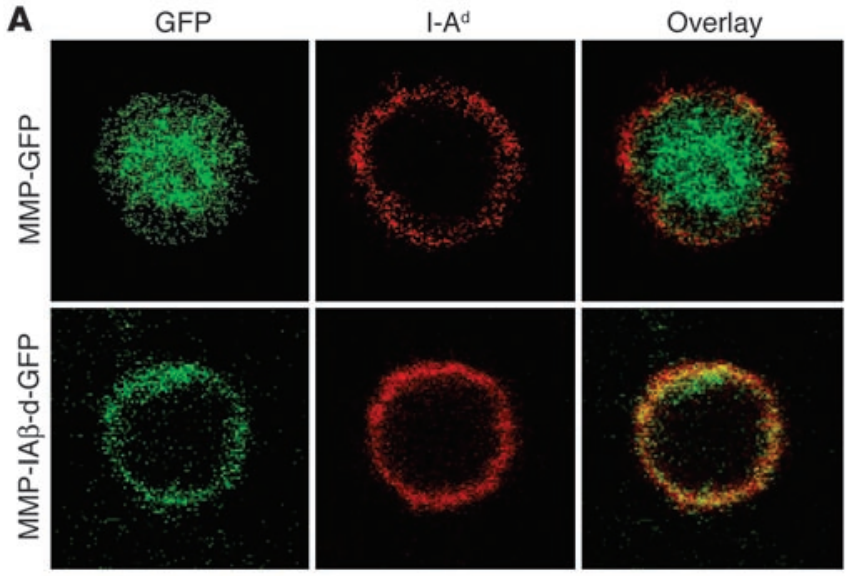

B
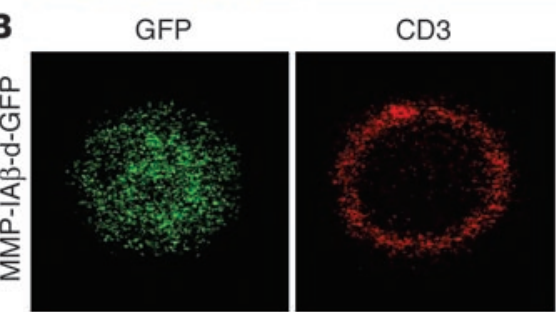

Overlay

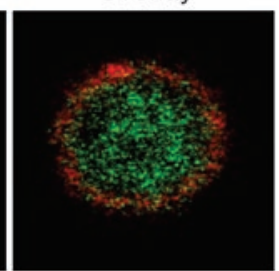


A

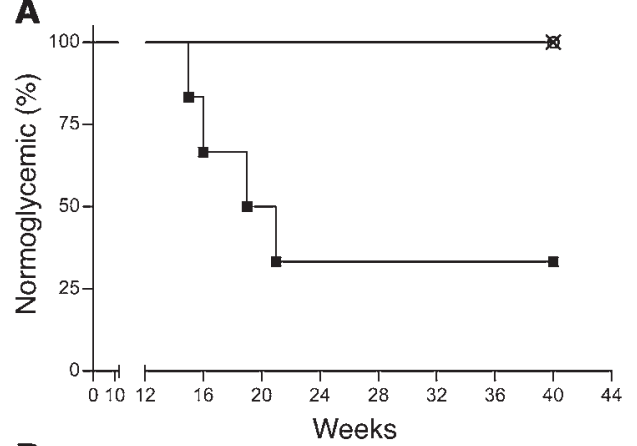

B

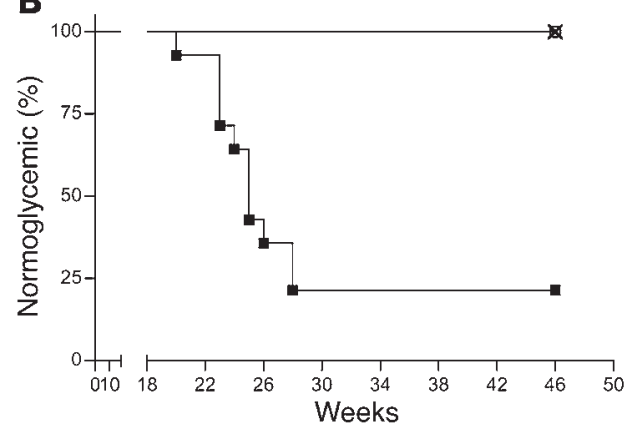

In contrast, mice reconstituted with either MMP-IA $\beta$-d-GFP- or MMP-IA $\beta$-k-GFP-transduced bone marrow were protected from disease and remained normoglycemic for 46 weeks after bone marrow transplantation (Figure $5 \mathrm{~B}$ ), when the experiment was terminated ( $P<0.001$ compared with MMP-GFP group, $n=24)$.

Expression of retrovirally encoded $M H C$ class II-GFP fusion genes in NOD mouse bone marrow-derived cells prevents insulitis. To examine

\section{Figure 6}

Prevention of insulitis in NOD mice reconstituted with MMP-IA $\beta$-dGFP- or MMP-IA $\beta$-k-GFP-transduced bone marrow. (A) NOD mice reconstituted with MMP-IA $\beta$-d-GFP-, MMP-IA $\beta$-k-GFP-, or MMPGFP-transduced bone marrow were sacrificed 20 weeks after transplantation. Pancreata were then harvested, fixed, paraffin-embedded, sectioned, and stained with anti-insulin antibodies, and counterstained with hematoxylin. Islets from mice reconstituted with MMP-GFPtransduced bone marrow showed significant mononuclear cell infiltration, and decreased storage of insulin (brown staining, top right panel). In contrast, islets from mice reconstituted with either MMPIA $\beta$-d-GFP-transduced (bottom left) or MMP-IA $\beta$-k-GFP-transduced bone marrow (bottom right) were free of cellular infiltration, and levels of insulin storage were comparable to those observed in tissue sections from control BALB/c pancreas (top left). Shown are representative sections from 3 independent experiments. (B) Cells infiltrating NOD islets are predominantly $\mathrm{CD}^{+}$. NOD mice reconstituted with MMP-IA $\beta$ d-GFP-, MMP-IA $\beta$-k-GFP-, or MMP-GFP-transduced bone marrow were sacrificed 20 weeks after bone marrow transplantation. Pancreata were snap-frozen, sectioned, fixed, and stained with antibodies specific for insulin (red) and CD3 (black), and then counterstained with hematoxylin (blue). Pancreata from NOD mice reconstituted with MMPGFP-transduced bone marrow (top right panel) show peri-islet infiltration of $\mathrm{CD}^{+}$cells, and little insulin staining. In contrast, pancreata from mice reconstituted with either MMP-IA $\beta$-d-GFP-transduced (bottom left) or MMP-IA $\beta$-k-GFP-transduced bone marrow (bottom right) had no visible cellular infiltrate, and insulin staining was comparable to that observed in control BALB/c pancreata (top left). Shown are representative sections from 3 independent experiments.

\section{Figure 5}

NOD mice reconstituted with either MMP-IA $\beta$-d-GFP- or MMP-IA $\beta$-kGFP-transduced bone marrow are protected from diabetes. (A) NOD mice were reconstituted with bone marrow retrovirally transduced with MMP-IA $\beta$-d-GFP (open circles, $n=6$ ), MMP-IA $\beta$-k-GFP $(\times, n=6$ ), or control MMP-GFP (filled squares, $n=6$ ). Shown are the percentages of normoglycemic mice at each time point after bone marrow transplantation. (B) NOD mice reconstituted with bone marrow retrovirally transduced with either MMP-IA $\beta$-d-GFP or MMP-IA $\beta$-k-GFP are protected from cyclophosphamide-induced diabetes. NOD mice were reconstituted with bone marrow transduced with MMP-IA $\beta$-d-GFP (open circles, $n=12$ ), MMP-IA $\beta$-k-GFP $(x, n=12)$, or control MMPGFP (filled squares, $n=14$ ). Twenty-one weeks after bone marrow transplantation, mice were injected intraperitoneally with $200 \mathrm{mg} / \mathrm{kg}$ cyclophosphamide. Shown are the percentages of normoglycemic mice at each time point after bone marrow transplantation. Data in $\mathbf{A}$ and $\mathbf{B}$ are the combined results of 2 independent experiments. In all experiments, blood glucose levels were measured weekly.

the effect of gene therapy on insulitis, pancreata were harvested from NOD mice reconstituted with MMP-IA $\beta$-d-GFP-, MMP-IA $\beta$ k-GFP-, or control MMP-GFP-transduced bone marrow 20 weeks after reconstitution. Tissue sections were prepared and stained with anti-insulin antibodies and hematoxylin. Pancreatic islets in mice reconstituted with MMP-GFP-transduced bone marrow exhibited significant cellular infiltration, and decreased storage of insulin ( $n=4$; Figure 6A). Cellular infiltrates consisted primarily of $\mathrm{T}$ cells, consistent with insulitis $(n=4$; Figure $6 \mathrm{~B})$. In contrast, islets from mice reconstituted with either MMP-IA $\beta$-d-GFP- or MMPIA $\beta$-k-GFP-transduced bone marrow exhibited normal histology $(n=4$; Figure 6A). Islets from these mice did not exhibit significant cellular infiltration, and insulin storage appeared to be similar to that observed in tissue sections of pancreata from normal
A

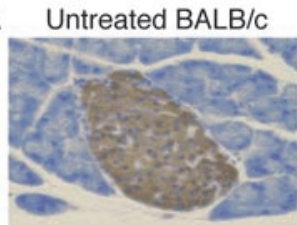

MMP-IA $\beta-d-G F P$

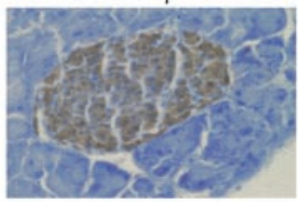

B

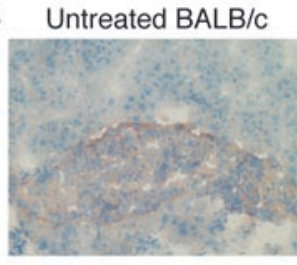

MMP-IAß-d-GFP

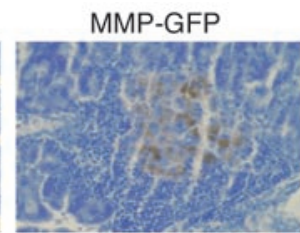

MMP-IAB-k-GFP

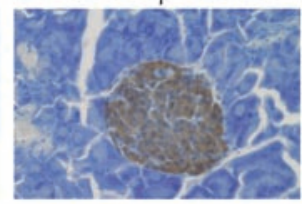

MMP-GFP

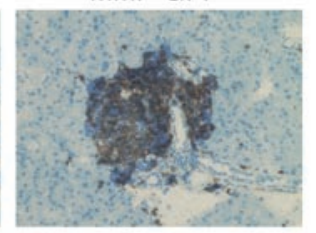

MMP-IA $\beta-k-G F P$
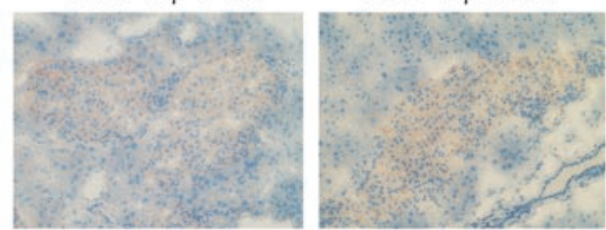

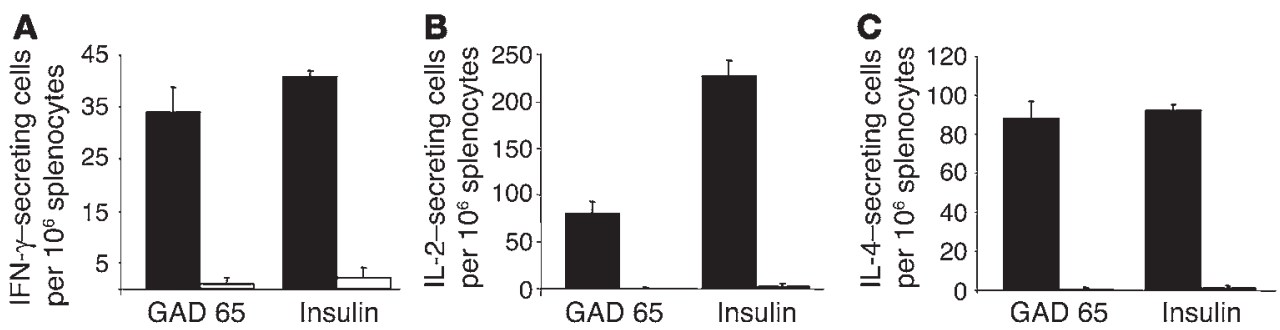

\section{Figure 7}

Expression of retrovirally transduced diabetes-resistant MHC class II genes in bone marrow-derived cells prevents the development of functional autoreactive T cells in NOD mice. Twenty to twenty-eight weeks after reconstitution, splenocytes were harvested from NOD mice reconstituted with MMP-IA $\beta$-d-GFP-, MMP-IA $\beta$-k-GFP-, or control MMP-GFP-transduced bone marrow. Single-cell suspensions were prepared and cultured overnight with whole insulin protein, GAD 65 peptide 206-220, or, as a control, peptide 85-99 of MBP. The frequency of cells producing IFN- $\gamma$ (A), IL-2 (B), and IL-4 (C) was then measured by cytokine ELISPOT assays. Responses to GAD 65 or insulin by splenocytes from NOD mice reconstituted with MMP-GFP-transduced bone marrow (black bars) were compared with responses to GAD 65 or insulin by cells from NOD mice reconstituted with either MMP-IA $\beta$-d-GFP- or MMP-IA $\beta$-k-GFP-transduced bone marrow (white bars). Shown is 1 representative experiment of 3.

$\mathrm{BALB} / \mathrm{c}$ controls. Similar results were observed at 40 weeks after reconstitution (not shown). These data suggest that expression of diabetes-resistant MHC genes from protective MHC haplotypes prevents insulitis and the development of islet antigen-reactive $\mathrm{T}$ cells that cause islet destruction.

Elimination of self-antigen-reactive T cells in NOD mice reconstituted with MHC class II-GFP-transduced bone marrow. We next examined the frequency of self-antigen-reactive T cells in NOD mice reconstituted with MMP-IA $\beta$-d-GFP-, MMP-IA $\beta$-k-GFP-, or control MMP-GFP-transduced syngeneic bone marrow using cytokine ELISPOT assays. Mice were sacrificed 20-28 weeks after reconstitution, and spleens were harvested. Splenocytes were then restimulated overnight with insulin (whole protein), peptide 206-220 from glutamic acid decarboxylase 65 (GAD 65), or peptide 85-99 from myelin basic protein (MBP) as a control in ELISPOT assays. The GAD 65 peptide was chosen because it is an immunodominant self-antigen peptide in NOD mice (33) and binds with high affinity to I-Ag7 (34). A significant frequency of spleen cells from NOD mice reconstituted with MMP-GFP-transduced bone marrow were able to secrete IFN- $\gamma\left(34 \pm 5\right.$ cells per $\left.10^{6}\right)$, IL-2 (80 \pm 12 cells per $\left.10^{6}\right)$, and IL-4 $\left(88 \pm 9\right.$ cells per $\left.10^{6}\right)$ in response to the GAD 65 peptide $(n=7 ;$ Figure 7$)$. In contrast, we were unable to detect production of IFN- $\gamma\left(1 \pm 1\right.$ cell per $\left.10^{6}, P<0.01\right)$, IL-2 (undetectable, $P<0.01$ ), or IL-4 (undetectable, $P<0.01$ ) in response to GAD 65 peptide by spleen cells from NOD mice reconstituted with either MMP-IA $\beta$-d-GFP- or MMP-IA $\beta$-k-GFP-transduced bone marrow (Figure 7). Similarly, a significant frequency of splenocytes from NOD mice reconstituted with control MMP-GFP-transduced bone marrow produced IFN- $\gamma\left(41 \pm 2\right.$ cells per $\left.10^{6}\right)$, IL-2 $(226 \pm 18$ cells per $\left.10^{6}\right)$, and IL-4 $\left(92 \pm 3\right.$ cells per $\left.10^{6}\right)$ in response to the insulin protein, while cells from NOD mice reconstituted with either MMP-IA $\beta$-d-GFP- or MMP-IA $\beta$-k-GFP-transduced bone marrow had significantly lower frequencies of cells producing IFN- $\gamma(2 \pm 2$ cells per $\left.10^{6}, P<0.01\right)$, IL-2 $\left(2 \pm 3\right.$ cells per $\left.10^{6}, P<0.001\right)$, and IL-4 $\left(1 \pm 1\right.$ cell per $\left.10^{6}, P<0.01\right)$ in response to insulin.

Thymic deletion of islet antigen-specific T cells in NOD mice reconstituted with MHC class II-GFP-transduced bone marrow. We reasoned that the elimination of functional islet-reactive $\mathrm{T}$ cells following expression of a retrovirally encoded diabetes-resistant $\mathrm{I}-\mathrm{A} \beta^{\mathrm{k}}$ or I-A $\beta^{\mathrm{d}}$ allele could result from either central deletion of islet-reactive clones in the thymus $(21,35)$, or peripheral inactivation of islet-reactive clones through regulatory mechanisms (36). To inves- tigate the mechanism by which functional islet-reactive $\mathrm{T}$ cells are eliminated, we used $\mathrm{I}_{-\mathrm{A}^{\mathrm{g}}}$ tetramers loaded with the peptide AAAAVRPLWVRMEAA (BDC-15) (37). This peptide, which was identified through the use of combinatorial peptide libraries (38), is known to stimulate islet-reactive $T$ cell clones that mediate insulitis and cause diabetes. The I-Ag7 tetramer loaded with BDC15 has been shown to bind a population of $\mathrm{T}$ cells in the thymus and pancreatic lymph nodes of NOD mice $(37,39)$. To determine whether expression of a retrovirally encoded diabetes-resistant $\mathrm{I}-\mathrm{A} \beta^{\mathrm{k}}$ or I-A $\beta^{\mathrm{d}}$ allele on bone marrow-derived cells resulted in thymic deletion, we used I-Ag7 tetramers loaded with the BDC-15 peptide to detect islet-reactive $\mathrm{T}$ cells in the thymus of NOD mice. Fiveto six-week-old NOD mice were irradiated and reconstituted with $4 \times 10^{6}$ syngeneic bone marrow cells transduced with either MMPIA $\beta$-d-GFP or control MMP-GFP virus. Eleven weeks after bone marrow transplantation, mice were sacrificed along with agematched naive NOD and BALB/c control mice, and single-cell thymocyte suspensions were prepared. Thymocytes were stained with anti-CD4 and anti-CD8 antibodies, annexin V, and I-Ag7 tetramers loaded with either the control CLIP peptide or BDC-15 peptide and analyzed by flow cytometry. As expected, we found that $\mathrm{I}-\mathrm{A}^{\mathrm{g}} / \mathrm{BDC}-15$ tetramers labeled a population of $\mathrm{CD}^{+} \mathrm{T}$ cells $(0.8 \%$; Figure $8 \mathrm{~A})$ in the thymus of naive NOD mice, but not in control BALB/c mice $(<0.1 \%)$. In mice reconstituted with bone marrow transduced with control MMP-GFP virus, $\mathrm{CD}^{+} \mathrm{T}$ cells in the thymus that were labeled with I-Ag7/BDC-15 tetramers were readily detectable at frequencies similar to those observed in naive NOD mice, suggesting that transduction and bone marrow transplantation alone do not affect the frequency of islet-reactive $\mathrm{T}$ cells. In contrast, the frequency of $\mathrm{CD}^{+} \mathrm{T}$ cells labeled with I-Ag7/BDC-15 tetramer was substantially reduced $(0.1 \%)$ in thymocytes from NOD mice reconstituted with bone marrow transduced with MMP-IA $\beta$ $\mathrm{d}$-GFP virus. In all samples, staining with the control I-As7/CLIP tetramer resulted in only background labeling (Figure 8A).

To determine at what stage of thymus development elimination of islet-reactive $T$ cells occurred, we gated on I-As7/BDC-15 tetramer-labeled cells and examined surface expression of CD4 and CD8. In both naive NOD mice and NOD mice reconstituted with bone marrow transduced with control MMP-GFP virus, the $\mathrm{I}-\mathrm{A}^{\mathrm{g}} / \mathrm{BDC}-15$ tetramer labeled both $\mathrm{CD} 4^{+} \mathrm{CD} 8^{+}$double-positive $\mathrm{T}$ cells and $\mathrm{CD}^{+} \mathrm{CD}^{-}$single-positive $\mathrm{T}$ cells (Figure $8 \mathrm{~B}$ ). In contrast, in NOD mice reconstituted with bone marrow transduced 

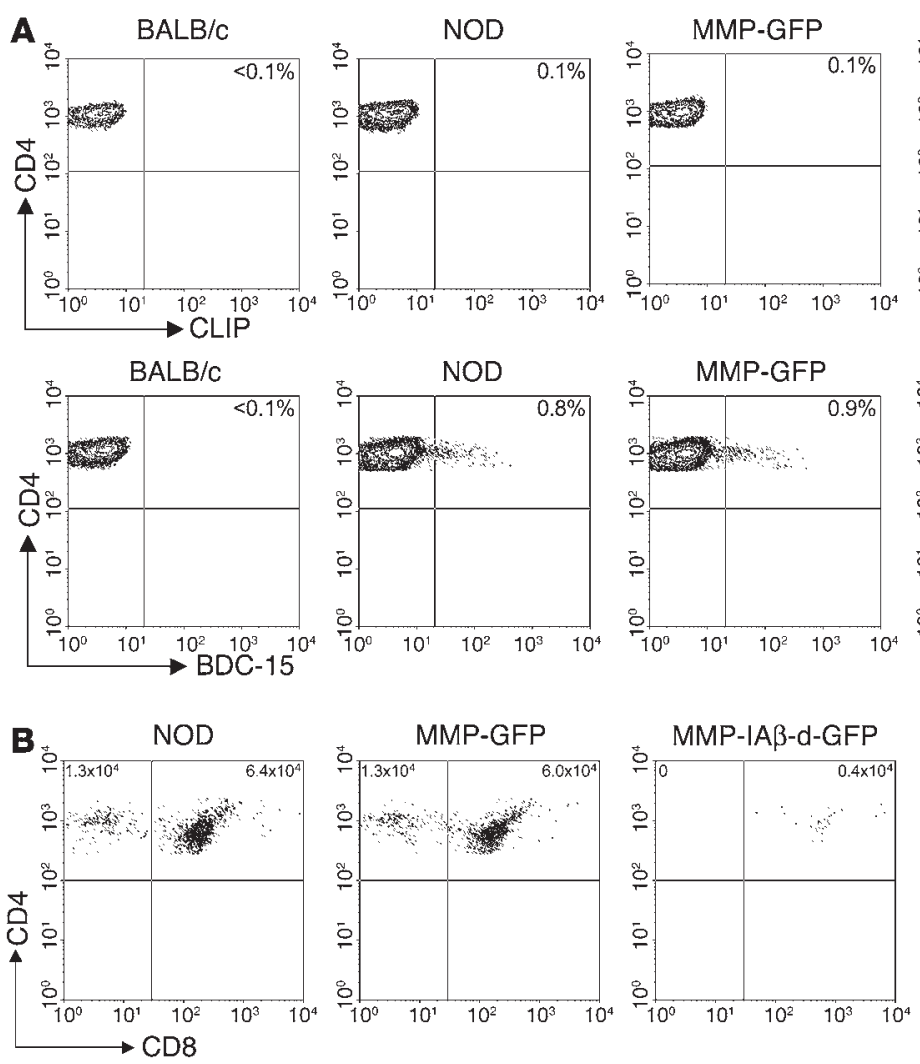

Figure 8

Central deletion of autoreactive T cells is mediated by retrovirally encoded MHC class II $\beta$ chain. Eleven weeks after bone marrow transplantation, NOD mice reconstituted with either MMP-IA $\beta-d-$ GFP- or control MMP-GFP-transduced bone marrow were sacrificed, and single-cell thymocyte suspensions were prepared. Single-cell suspensions were also prepared from naive age-matched NOD and BALB/c control mice. Thymocytes were stained with anti-CD4 and anti-CD8 antibodies, annexin V, and I-A $\mathrm{A}^{\mathrm{g}}$ tetramers loaded with either the control CLIP peptide or $\mathrm{BDC}-15$ peptide, and analyzed by flow cytometry. (A) Single-positive CD4 T cells from mice reconstituted with bone marrow transduced with MMP-IA $\beta$-d-GFP do not bind I-A97/BDC-15 tetramers. Cells were gated on live annexin $\mathrm{V}^{-} \mathrm{CD} 4{ }^{+}{ }^{C D} 8^{-}$single-positive CD4 T cells. The percentage of these cells that bound to I-A ${ }^{97 / C L I P ~(t o p ~}$ row) and I-Ag7/BDC-15 tetramers (bottom row) is shown in the upper right quadrant. Shown is 1 representative experiment of 3. (B) Specific deletion of I-A97/BDC-15-binding T cells in mice reconstituted with bone marrow transduced with MMP-IA $\beta$-d-GFP. Shown is expression of CD4 and CD8 after gating on I-A ${ }^{97 / B D C-15}$ tetramer ${ }^{+}$, annexin $\mathrm{V}^{-}$(live) cells. The total number of $\mathrm{CD}^{+}{ }^{+}$single-positive $\mathrm{T}$ cells that bound the $\mathrm{I}-\mathrm{A}^{\mathrm{g}} / \mathrm{BDC}-15$ tetramer was calculated by multiplication of the frequency of these cells by the total number of thymocytes recovered and is shown in the upper left quadrant. The total number of $\mathrm{CD} 4{ }^{+} \mathrm{CD}^{+}$double-positive thymocytes that bound the $\mathrm{I}-\mathrm{A}^{97} / \mathrm{BDC}-15$ tetramer was calculated similarly and is shown in the upper right quadrant. One representative experiment of 3 is shown.

with MMP-IA $\beta$-d-GFP virus, the I-A ${ }^{\mathrm{g} 7} / \mathrm{BDC}-15$ tetramer labeled $\mathrm{CD}^{+}{ }^{+} \mathrm{CD} 8^{+}$double-positive $\mathrm{T}$ cells, but not $\mathrm{CD}^{+}{ }^{+} \mathrm{CD} 8^{-}$single-positive $\mathrm{T}$ cells. Naive NOD mice had similar numbers of $\mathrm{CD} 4^{+} \mathrm{CD} 8^{+}$ double-positive T cells $\left(6.4 \times 10^{4}\right)$ compared with NOD mice reconstituted with bone marrow transduced with control MMPGFP virus $\left(6.0 \times 10^{4}\right)$, while NOD mice reconstituted with bone marrow transduced with MMP-IA $\beta$-d-GFP virus had a reduced number $\left(0.4 \times 10^{4}\right)$. Note that the I-A ${ }^{7} / \mathrm{BDC}-15$ tetramer is able to bind cells that express retrovirally encoded MHC class II alleles, since these cells express both I-A $\mathrm{A}^{7}$ and I-A $\beta$ chains. Together, these data suggest that $\mathrm{CD} 4^{+} \mathrm{T}$ cells expressing a $\mathrm{T}$ cell receptor that binds the I- $\mathrm{A}^{\mathrm{g}} / \mathrm{BDC}-15$ tetramer are negatively selected in the thymus of mice that express retrovirally encoded diabetes-resistant MHC class II alleles.
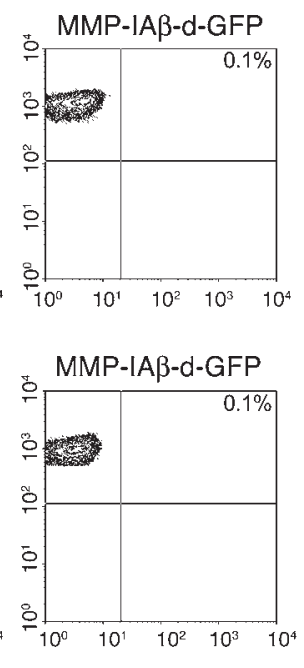

\section{Discussion}

Multiple genes contribute to the development of type 1 diabetes; however, inheritance of particular MHC alleles is the most significant determining factor (40). NOD mice that express MHC class II alleles other than $\mathrm{I}-\mathrm{A}^{\mathrm{g} 7}$ are protected from development of diabetes (16-18, $21,41-44)$, which supports the notion that MHC plays a significant role in type 1 diabetes. However, it has been unclear whether protection results from negative selection of self-antigen-reactive $\mathrm{T}$ cells on diabetes-resistant MHC expressed in the thymus, or positive selection of regulatory $\mathrm{T}$ cells that can control disease progression. The role of MHC in bone marrow transplantation studies is perhaps less clear, because wild-type bone marrow cells express genes in addition to diabetes-resistant MHC that could influence disease progression (24-28).

Our data suggest that expression of MHC class II genes associated with protection from diabetes in hematopoietic cells of NOD mice alone is sufficient to prevent diabetes occurrence. Expression of diabetes-resistant MHC class II $\beta$ chains prevented the development of functional $\mathrm{T}$ cells that respond to self-antigens that are known to be targets of $\mathrm{T}$ cell-mediated destruction of pancreatic $\beta$ cells. In addition, expression of diabetes-resistant MHC class II $\beta$ chains prevented $\mathrm{T}$ cell infiltration and insulitis. Furthermore, NOD mice expressing I-A $\mathrm{A}^{\mathrm{d}}$ or I-A $\mathrm{A}^{\mathrm{k}} \mathrm{MHC}$ class II $\beta$ chains on bone marrow-derived cells were protected from diabetes occurrence following administration of cyclophosphamide, a drug that is known to accelerate the development of diabetes in NOD mice. Together these data suggest that gene therapy approaches provide robust protection from $T$ cell-mediated autoimmunity.

Several $\mathrm{T}$ cell clones that recognize islet antigens have been isolated from NOD mice. Transfer of one of these $\mathrm{T}$ cell clones, $\mathrm{BDC} 2.5$, into $\mathrm{NOD} /$ scid mice results in the rapid development of diabetes (45). Although the identity of the autoantigen that these clones recognize is not known, a peptide mimetic that stimulates most of these clones at low peptide concentrations had been identified, and an MHC class II tetramer to which the peptide mimetic is bound will label both these BDC2.5 T cells and a population of $\mathrm{CD}^{+} \mathrm{T}$ cells in the lymph nodes and thymus of prediabetic NOD mice. Expansion of the population of tetramer/peptide mimetic binding autoreactive $\mathrm{T}$ cells correlates with increased insulitis and the onset of diabetes $(37,39)$. Using this reagent, we stained thymocytes from either mice expressing retrovirally transduced diabetes-resistant MHC class II $\beta$ chains on bone marrow cells, 
or mice expressing only GFP in bone marrow-derived cells. The thymus of naive NOD and control mice contained a substantial population of $\mathrm{CD}^{+} \mathrm{CD}^{-}$single-positive $\mathrm{T}$ cells able to bind the tetramer/peptide complex. In contrast, tetramer-binding $\mathrm{CD}^{+} \mathrm{CD}^{-}$single-positive $\mathrm{T}$ cells were not detected in the thymus of mice expressing the diabetes-resistant MHC class II $\beta$ chain on bone marrow-derived cells. These data suggest that the expression of diabetes-resistant MHC class II $\beta$ chain is sufficient to prevent the development of these autoreactive $T$ cells in the thymus.

Failure to develop autoreactive $\mathrm{T}$ cells in these mice may be due to either negative selection of autoreactive clones, or failure to positively select these $T$ cells. Bone marrow-derived cells lack the ability to positively select $T$ cells $(46,47)$ but are potent mediators of negative selection (48-51), which suggests that the lack of functional self-reactive $\mathrm{T}$ cells in NOD mice reconstituted with retrovirally transduced bone marrow is related to the ability of transduced MHC class II genes expressed on bone marrow-derived cells to mediate negative selection of self-reactive $\mathrm{T}$ cells in the thymus. Our data demonstrate that $\mathrm{CD} 4^{+} \mathrm{CD} 8^{+/ 10}$ double-positive as well as $\mathrm{CD}^{+}$single-positive $\mathrm{T}$ cells in the thymus of control mice receiving MMP-GFP-transduced bone marrow were able to bind the BDC- 15 tetramer. The absolute number of $\mathrm{CD} 4^{+} \mathrm{CD} 8^{+/ 1}$ double-positive $\mathrm{T}$ cells able to bind the BDC-15 tetramer was lower in mice reconstituted with MHC class II-transduced bone marrow. Furthermore, we were unable to detect tetramer-binding $\mathrm{CD}^{+}$single-positive $\mathrm{T}$ cells in these mice. These data suggest that islet antigen-reactive $\mathrm{T}$ cells are able to develop to the double-positive stage of T cell development in mice reconstituted with MHC class II $\beta$ chain-transduced bone marrow and are then negatively selected. Consistent with this idea, we have observed that expression of retrovirally transduced allogeneic MHC antigens on bone marrow-derived cells results in negative selection of alloantigenreactive $T$ cells in the thymus (52).

Other gene therapy strategies aimed at modifying host islet autoimmunity include the introduction of cytokine genes such as IL-10 (53-58), IL-4 (59-63), TGF- $\beta$ (64), and IFN- $\gamma$ receptor $(65,66)$, and blockade of costimulatory molecules $(67,68)$. Promising results have been obtained in animal models; however, all of these strategies are geared toward downregulation of existing autoimmune $\mathrm{T}$ cells. It is likely therefore, that the more effective of these strategies will cause nonspecific immunosuppression in recipients. However, the disadvantages of long-term immunosuppression are well documented and include increased risk of malignancy and infection. Using genetic engineering to confer expression of diabetes-resistant MHC class II alleles, we show the specific deletion of islet-reactive T cells, and animals are not otherwise immunocompromised.

Several lines of evidence suggest that, in humans, once destructive anti-islet immune responses have developed, an asymptomatic period precedes onset of clinical disease for several months to years (reviewed in ref. 69). In addition, in many patients, even at disease onset there is evidence of residual $\beta$ cell function as demonstrated by c-peptide secretion. Consequently, the elimination of autoimmunity early after disease onset has the potential to substantially ameliorate type 1 diabetes. One possible intervention is the transplantation of allogeneic bone marrow cells, which can prevent diabetes in NOD mice $(1,24-28)$. However, transplantation of allogeneic bone marrow carries with it the risk of inducing graft-versus-host disease, which can be fatal, and the conditioning regimen required for allogeneic engraftment makes this therapy unsuitable for treatment of prediabetic patients. Our data suggest that expression of MHC class II genes associated with protection from diabetes through genetic engineering of hematopoietic stem cells could prevent type 1 diabetes in individuals that express MHC alleles associated with susceptibility to disease and exhibit signs of diminishing insulin response. Since this approach involves genetic modification of autologous hematopoietic progenitors to establish molecular rather than cellular chimerism (70), problems such as graft-versus-host disease that are associated with transplantation of allogeneic bone marrow are eliminated. In addition, our data show that diabetes can be prevented with relatively low levels of expression of diabetes-resistant MHC alleles. This suggests that the conditioning regimen required to achieve sufficient engraftment of genetically modified bone marrow progenitors to prevent diabetes may be substantially less rigorous than that required for allogeneic bone marrow transplantation.

For islet transplantation to be successful as a long-term cure for type 1 diabetes (71-73), it is necessary to overcome the underlying problem of autoimmunity that leads to diabetes occurrence and destruction of the transplanted islets (74). Our data demonstrate that the introduction of diabetes-resistant MHC class II $\beta$ chain on bone marrow-derived cells is sufficient to prevent the development of functional islet-reactive $\mathrm{T}$ cells, and to mediate the intrathymic deletion of these cells. This may be of clinical significance in the context of islet transplantation, and this approach could also be used to prevent the recurrence of autoimmunity after islet transplantation.

\section{Methods}

Mice. NOD/MrkTac mice were purchased from Taconic. BALB/c mice were purchased from The Jackson Laboratory. Four- to six-week-old female mice were used in all experiments. All experiments were performed in accordance with institutional guidelines.

Vector construction. Full-length cDNAs encoding I-A $\beta^{\mathrm{d}}$ and I-A $\beta^{\mathrm{k}}$ were cloned by RT-PCR from BALB/c or CBA/Ca spleen cells, respectively. The products were ligated into pEGFP-N2 (BD Biosciences - Clontech) inframe with eGFP. Genes encoding I-A $\beta$-GFP fusion proteins were then cloned into the pMMPf 2 vector (a kind gift of Richard Mulligan, Children's Hospital, Boston, Massachusetts, USA) to generate pMMP-IA $\beta$-d-GFP and pMMP-IA $\beta$-k-GFP. The MMP retroviral vector is a derivative of MFG (75).

Production of recombinant retroviruses. Virus preparations were made at the Harvard Institute of Human Genetics (Boston, Massachusetts, USA) in collaboration with Richard Mulligan (Harvard Gene Therapy Initiative). Virus preparations tested negative for helper virus contamination. The titers of retroviral supernatants used in this study were between $3 \times 10^{6}$ and $5 \times 10^{6}$ infectious particles per milliliter. Control MMP-GFP retrovirus was kindly provided by Richard Mulligan through the Harvard Gene Therapy Initiative.

Transduction of M12.C3 and A20 cell lines. The M12.C3 cell line was the kind gift of Laurie Glimcher (Harvard Medical School). The A20 cell line was purchased from the American Type Culture Collection. In each case, $10^{6}$ cells were plated 24 hours prior to transduction, and $1 \mathrm{ml}$ viral supernatant was added to the cells at 24 -hour intervals over 3 days. The cells were then washed and cultured for an additional 48 hours prior to analysis by flow cytometry.

Bone marrow transduction and transplantation. Bone marrow cells were transduced as described previously (31). The multiplicity of infection (MOI) used was 2.2 for MMP-IA $\beta$-d-GFP-transduced, 1.9 for MMP-IA $\beta$-k-GFPtransduced, and 3 for MMP-GFP-transduced cells. After 96 hours in culture, cells were harvested and washed to remove excess virus, and $4 \times 10^{6}$ cells were injected intravenously into preconditioned recipients. Recipients were preconditioned with 10.25 Gy irradiation 1 day prior to bone marrow transplantation. In some experiments, recipients were treated with $0.5 \mathrm{mg}$ of the anti-CD4 antibody GK1.5 (76), and $0.5 \mathrm{mg}$ of the anti-CD8 antibody 116-13.1 (77). 
Antibodies. Monoclonal antibodies specific for CD4 (RM4-5), CD8 (53-6.7), CD3 (145-2C11), Ly-6G (Gr-1, RB6-8C5), B220 (RA3-6B2), CD11b (Mac-1, M1/70), NK cells (DX5), CD11c (HL3), $\operatorname{IgG}_{2 \mathrm{a}}$ (19-15), GFP (JL-8), $\mathrm{I}-\mathrm{A}^{\mathrm{d}}(39-10-8)$, and $\mathrm{I}-\mathrm{A} \beta^{\mathrm{k}}$ (10-3.6) were obtained from BD Biosciences Pharmingen. Polyclonal guinea pig anti-porcine insulin antibodies were obtained from DAKO Corp. Phycoerythrin-conjugated (PE-conjugated) anti-mouse CD3 (17A2; BD Biosciences - Pharmingen) was used for confocal microscopy studies.

Immunofluorescence and confocal microscopy. Eighteen weeks after bone marrow transplantation, PBMCs were collected from mice reconstituted with either MMP-IA $\beta$-d-GFP- or MMP-GFP-transduced bone marrow and stained with either biotin-conjugated $39-10-8$ or PE-conjugated $17 \mathrm{~A} 2$ for 30 minutes. Samples stained with 39-10-8 were incubated for an additional 30 minutes with PE-conjugated streptavidin (BD Biosciences - Pharmingen). The cells were then permeabilized with $0.1 \%$ Triton X-100 and stained with JL- 8 for 30 minutes at $4^{\circ} \mathrm{C}$. JL- 8 binding was revealed by staining with FITC-conjugated anti-mouse $\operatorname{IgG}_{2 \mathrm{a}}$. Samples were then analyzed by confocal microscopy.

Blood glucose levels. Blood glucose levels were monitored weekly using a standard glucometer. Two consecutive readings of greater than $300 \mathrm{mg} / \mathrm{dl}$ were considered to be indicative of the development of hyperglycemia.

ELISPOT. Cytokine ELISPOT assays were performed using HA plates (Millipore Corp.) according to the manufacturer's specifications. BVD1D11 (anti-IL-4), JES6-1A12 (anti-IL-2), and R4-6A2 (anti-IFN- $\gamma$ ) (Caltag Laboratories Inc.) were used at $10 \mu \mathrm{g} / \mathrm{ml}$ to coat plates. In ELISPOT assays, $10^{6}$ (for IL-4), $0.5 \times 10^{6}$ (for IL-2), or $3 \times 10^{6}$ (for IFN- $\gamma$ ) splenocytes were added to each well. Cells were cultured overnight with $0.1 \mathrm{mg} / \mathrm{ml}$ insulin (Sigma-Aldrich), MBP peptide (peptide 85-99, ENPVVHFFKNIVTPR), or GAD 65 peptide (peptide 206-220, TYEIAPVFVLLEYVT). Peptides were obtained from Invitrogen Corp. Cytokine production was detected using $10 \mu \mathrm{g} / \mathrm{ml}$ biotinylated BVD-24G2, JES6-5H4, and XMG1.2 (Caltag Laboratories Inc.). Assays were performed in triplicate and averaged. To calculate the specific response to GAD 65 and insulin, the average background response to $\mathrm{MBP}$ was subtracted. There was no significant difference in the response to MBP peptide between the groups (not shown).

Histology. One half of each pancreas analyzed was fixed in $10 \%$ buffered formalin and processed for paraffin embedding. The remaining half was snap-frozen in OCT compound (Tissue-Tek; Sakura Finetek USA Inc.). Paraffin-embedded tissue sections $(5 \mu \mathrm{m})$ were stained with guinea pig anti-porcine insulin antibody for 15 minutes and stained with a biotinylated goat anti-guinea pig secondary antibody (Vector Laboratories Inc.) for 30 minutes. Sections were developed using $\mathrm{ABC}$ solution and 3,3'-diaminobenzidine (Vector Laboratories Inc.) and counterstained with hematoxylin. Frozen samples were stained with biotin-conjugated 1452C11 for 30 minutes and developed with $\mathrm{ABC}$ solution (Vector Laboratories Inc.) and 3,3'-diaminobenzidine/nickel. Sections were then stained with anti-insulin antibodies for 15 minutes, followed by biotin-conjugated goat anti-guinea pig secondary antibody (Vector Laboratories Inc.) for 30 minutes. The sections were incubated with streptavidin-HRP (Amersham Biosciences) and developed with AEC substrate-chromogen (DAKO Corp.) according to the manufacturer's instructions. Coverslips were mounted after counterstaining with hematoxylin.

MHC class II tetramer staining. Biotinylated, MHC class II monomers were prepared as previously described (37). The tetramers were loaded with the BDC-15 peptide, which differs from the previously used BDC- 13 peptide by the addition of an alanine residue at both the $\mathrm{N}$ - and the $\mathrm{C}$-terminus (AAAAVRPLWVRMEAA). Both BDC-13 and BDC-15 provide similar levels of labeling. To form tetramers, biotinylated MHC class II monomers and streptavidin-PE (Invitrogen Corp.) were mixed at a molar ratio of $4: 1$ and incubated for 1 hour. The tetramer was then incubated with $5 \times 10^{6}$ thymocytes at a final concentration of $10 \mu \mathrm{g} / \mathrm{ml}$ for 30 minutes. Cells were additionally stained with anti-CD4 (RM4-5; BD Biosciences - Pharmingen), anti-CD8a (53-6.7; BD Biosciences - Pharmingen), and annexin $\mathrm{V}$ (BD Biosciences - Pharmingen) for 20 minutes.

\section{Acknowledgments}

We thank Richard C. Mulligan and Jeng-Shin Lee for the MMP retroviral vector and packaging system and for technical advice; and the Harvard Gene Therapy Initiative Vector Core, supported in part by the Association Française contre les Myopathies, for production of retroviruses. In addition, we thank Xandra Breakefield and Gerald L. Waneck for critical review of the manuscript, and members of the Iacomini laboratory for helpful discussions. We thank Denise Malkowski and Lee Bar-Sagi for expert technical assistance. This work was supported in part by NIH grants R01 AI44268 and R01 AI43619 (to J. Iacomini).

Received for publication May 7, 2004, and accepted in revised form July 20, 2004.

Address correspondence to: John Iacomini, Massachusetts General Hospital, 149-5210, 13th Street, Boston, Massachusetts 02129, USA. Phone: (617) 724-9846; Fax: (617) 724-9218; E-mail: john.iacomini@tbrc.mgh.harvard.edu.
1. Wicker, L.S., Todd, J.A., and Peterson, L.B. 1995 Genetic control of autoimmune diabetes in the NOD mouse. Annu. Rev. Immunol. 13:179-200.

2. Nepom, G.T., and Kwok, W.W. 1998. Molecular basis for HLA-DQ associations with IDDM. Diabetes. 47:1177-1184.

3. McDevitt, H. 1998. The role of MHC class II molecules in susceptibility and resistance to autoimmunity. Curr. Opin. Immunol. 10:677-681.

4. Morel, P.A., Dorman, J.S., Todd, J.A., McDevitt, H.O., and Trucco, M. 1988. Aspartic acid at position 57 of the HLA-DQ beta chain protects against Type I diabetes: a family study. Proc. Natl. Acad. Sci. U. S. A. 85:8111-8115.

5. Ilonen, J., et al. 2002. Estimation of genetic risk for type 1 diabetes. Am. J. Med. Genet. 115:30-36.

6. Atkinson, M.A., and Leiter, E.H. 1999. The NOD mouse model of type 1 diabetes: as good as it gets? Nat. Med. 5:601-604.

7. Hattori, M., et al. 1986. The NOD mouse: recessive diabetogenic gene in the major histocompatibility complex. Science. 231:733-735.
8. Lee, K.H., Wucherpfennig, K.W., and Wiley, D.C. 2001. Structure of a human insulin peptide-HLADQ8 complex and susceptibility to type 1 diabetes. Nat. Immunol. 2:501-507.

9. Stratmann, T., et al. 2000. The I-Ag7 MHC class II molecule linked to murine diabetes is a promiscuous peptide binder. J. Immunol. 165:3214-3225.

10. Ettinger, R.A., Liu, A.W., Nepom, G.T., and Kwok, W.W. 1998. Exceptional stability of the HLADQA $1 * 0102 / \mathrm{DQB} 1 * 0602 \alpha \beta$ protein dimer, the class II MHC molecule associated with protection from insulin-dependent diabetes mellitus. J. Immunol. 161:6439-6445.

11. Corper, A.L., et al. 2000. A structural framework for deciphering the link between I-Ag7 and autoimmune diabetes. Science. 288:505-511.

12. Abraham, R.S., Kudva, Y.C., Wilson, S.B., Strominger, J.L., and David, C.S. 2000. Co-expression of HLA DR3 and DQ8 results in the development of spontaneous insulitis and loss of tolerance to GAD65 in transgenic mice. Diabetes. 49:548-554.

13. Acha-Orbea, H., and McDevitt, H.O. 1987. The first external domain of the nonobese diabetic mouse class II I-A beta chain is unique. Proc. Natl. Acad. Sci. U. S. A. 84:2435-2439.

14. Todd, J.A., et al. 1988. A molecular basis for MHC class II-associated autoimmunity. Science. 240:1003-1009.

15. Luhder, F., Katz, J., Benoist, C., and Mathis, D. 1998. Major histocompatibility complex class II molecules can protect from diabetes by positively selecting $\mathrm{T}$ cells with additional specificities. J. Exp. Med. 187:379-387.

16. Uehira, M., et al. 1989. Development of autoimmune insulitis is prevented in $\mathrm{E}$ alpha $\mathrm{d}$ but not in A beta $\mathrm{k}$ NOD transgenic mice. Int. Immunol. 1:209-213.

17. Reich, E.P., Sherwin, R.S., Kanagawa, O., and Janeway, C.A.J. 1989. An explanation for the protective effect of the MHC class II I-E molecule in murine diabetes. Nature. 341:326-328.

18. Lund, T., et al. 1990. Prevention of insulin-dependent diabetes mellitus in non-obese diabetic mice by transgenes encoding modified I-A beta-chain or normal I-E alpha-chain. Nature. 345:727-729. 
19. Slattery, R.M., et al. 1990. Prevention of diabetes in non-obese diabetic I-Ak transgenic mice. Nature. 345:724-726

20. Miyazaki, T., et al. 1990. Direct evidence for the contribution of the unique I-ANOD to the development of insulitis in non-obese diabetic mice. Nature. 345:722-724

21. Schmidt, D., Verdaguer, J., Averill, N., and Santamaria, P. 1997. A mechanism for the major histocompatibility complex-linked resistance to autoimmunity. J. Exp. Med. 186:1059-1075.

22. Singer, S.M., et al. 1998. Prevention of diabetes in NOD mice by a mutated I-Ab transgene. Diabetes. 47:1570-1577.

23. Singer, S.M., Tisch, R., Yang, X.D., and McDevitt, H.O. 1993. An Abd transgene prevents diabetes in nonobese diabetic mice by inducing regulatory $\mathrm{T}$ cells. Proc. Natl. Acad. Sci. U. S. A. 90:9566-9570.

24. LaFace, D.M., and Peck, A.B. 1989. Reciprocal allogeneic bone marrow transplantation between NOD mice and diabetes-nonsusceptible mice associated with transfer and prevention of autoimmune diabetes. Diabetes. 38:894-901.

25. Naji, A., Silvers, W.K., Bellgrau, D., and Barker, C.F. 1981. Spontaneous diabetes in rats: destruction of islets is prevented by immunological tolerance. Science. 213:1390-1392.

26. Seung, E., et al. 2000. Allogeneic hematopoietic chimerism in mice treated with sublethal myeloablation and anti-CD154 antibody: absence of graft-versus-host disease, induction of skin allograft tolerance, and prevention of recurrent autoimmunity in isletallografted NOD/Lt mice. Blood. 95:2175-2182.

27. Beilhack, G.F., et al. 2003. Purified allogeneic hematopoietic stem cell transplantation blocks diabetes pathogenesis in NOD mice. Diabetes. 52:59-68.

28. Li, H., et al. 1996. Mixed allogeneic chimerism induced by a sublethal approach prevents autoimmune diabetes and reverses insulitis in nonobese diabetic (NOD) mice. J. Immunol. 156:380-388.

29. Pearson, T., et al. 2003. Islet cell autoimmunity and transplantation tolerance: two distinct mechanisms? Ann. N. Y. Acad. Sci. 1005:148-156.

30. Glimcher, L.H., et al. 1983. IA mutant functional antigen-presenting cell lines. J. Immunol. 130:2287-2294.

31. Bracy, J.L., and Iacomini, J. 2000. Induction of B cell tolerance by retroviral gene therapy. Blood. 96:3008-3015

32. Andre-Schmutz, I., Hindelang, C., Benoist, C., and Mathis, D. 1999. Cellular and molecular changes accompanying the progression from insulitis to diabetes. Eur. J. Immunol. 29:245-255.

33. Chao, C.C., Sytwu, H.K., Chen, E.L., Toma, J., and McDevitt, H. 1999. The role of MHC class II molecules in susceptibility to type I diabetes: identification of peptide epitopes and characterization of the T cell repertoire. Proc. Natl. Acad. Sci. U. S. A. 96:9299-9304.

34. Hausmann, D.H.F., Yu, B., Hausmann, S., and Wucherpfennig, K.W. 1999. pH-dependent peptide binding properties of the type I diabetes-associated I-Ag7 molecule: rapid release of CLIP at an endosomal pH. J. Exp. Med. 189:1723-1733.

35. Schmidt, D., Amrani, A., Verdaguer, J., Bou, S., and Santamaria, P. 1999. Autoantigen-independent deletion of diabetogenic $\mathrm{CD} 4+$ thymocytes by protective MHC class II molecules. J. Immunol. 162:4627-4636.

36. Singer, S.M., Tisch, R., Yang, X.D., and McDevitt, H.O. 1993. An Abd transgene prevents diabetes in nonobese diabetic mice by inducing regulatory $\mathrm{T}$ cells. Proc. Natl. Acad. Sci. U. S. A. 90:9566-9570.

37. Jang, M.H., Seth, N.P., and Wucherpfennig, K.W. 2003. Ex vivo analysis of thymic CD4 T cells in nonobese diabetic mice with tetramers generated from I-A(g7)/class II-associated invariant chain peptide precursors. J. Immunol. 171:4175-4186.

38. Judkowski, V., et al. 2001. Identification of MHC class II-restricted peptide ligands, including a glutamic acid decarboxylase 65 sequence, that stimulate diabetogenic T cells from transgenic BDC2.5 nonobese diabetic mice. J. Immunol. 166:908-917.

39. You, S., et al. 2003. Detection and characterization of $\mathrm{T}$ cells specific for BDC2.5 T cell-stimulating peptides. J. Immunol. 170:4011-4020.

40. Vyse, T.J., and Todd, J.A. 1996. Genetic analysis of autoimmune disease. Cell. 85:311-318.

41. Slattery, R.M., et al. 1990. Prevention of diabetes in non-obese diabetic I-Ak transgenic mice. Nature. 345:724-726.

42. Miyazaki, T., et al. 1990. Direct evidence for the contribution of the unique I-ANOD to the development of insulitis in non-obese diabetic mice. Nature. 345:722-724

43. Singer, S.M., et al. 1998. Prevention of diabetes in NOD mice by a mutated I-Ab transgene. Diabetes. 47:1570-1577

44. Singer, S.M., Tisch, R., Yang, X.D., and McDevitt, H.O. 1993. An Abd transgene prevents diabetes in nonobese diabetic mice by inducing regulatory $\mathrm{T}$ cells. Proc. Natl. Acad. Sci. U. S. A. 90:9566-9570.

45. Haskins, K., and McDuffie, M. 1990. Acceleration of diabetes in young NOD mice with a CD4+ isletspecific T cell clone. Science. 249:1433-1436.

46. Markowitz, J.S., Auchincloss, H., Jr., Grusby, M.J., and Glimcher, L.H. 1993. Class II-positive hematopoietic cells cannot mediate positive selection of $\mathrm{CD}^{+} \mathrm{T}$ lymphocytes in class II-deficient mice. Proc. Natl. Acad. Sci. U. S. A. 90:2779-2783.

47. Urdahl, K.B., Sun, J.C., and Bevan, M.J. 2002. Positive selection of MHC class Ib-restricted CD8(+) T cells on hematopoietic cells. Nat. Immunol. 3:772-779.

48. Jenkinson, E.J., Anderson, G., and Owen, J.J. 1992. Studies on $\mathrm{T}$ cell maturation on defined thymic stromal cell populations in vitro. J. Exp. Med. 176:845-853.

49. Brocker, T., Riedinger, M., and Karjalainen, K 1997. Targeted expression of major histocompatibility complex (MHC) class II molecules demonstrates that dendritic cells can induce negative but not positive selection of thymocytes in vivo. J. Exp. Med. 185:541-550.

50. Owen, R.D. 1945. Immunogenetic consequences of vascular anastomoses between bovine twins. Science. 102:400-401.

51. Billingham, R.E., Brent, L., and Medawar, P.B. 1953. Actively acquired tolerance to foreign cells. Nature. 172:603-606

52. Kang, E.S., and Iacomini, J. 2002. Induction of central deletional $\mathrm{T}$ cell tolerance by gene therapy. J. Immunol. 169:1930-1935.

53. Ko, K.S., Lee, M., Koh, J.J., and Kim, S.W. 2001. Combined administration of plasmids encoding IL-4 and IL-10 prevents the development of autoimmune diabetes in nonobese diabetic mice. Mol. Ther. 4:313-316

54. Koh, J.J., et al. 2000. Degradable polymeric carrier for the delivery of IL-10 plasmid DNA to prevent autoimmune insulitis of NOD mice. Gene Ther. 7:2099-2104

55. Goudy, K., et al. 2001. Adeno-associated virus vector-mediated IL-10 gene delivery prevents type 1 diabetes in NOD mice. Proc. Natl. Acad. Sci. U. S. A. 98:13913-13918.

56. Zhang, Y.C., et al. 2003. Adeno-associated virusmediated IL-10 gene therapy inhibits diabetes recurrence in syngeneic islet cell transplantation of NOD mice. Diabetes. 52:708-716.

57. Yang, Z., et al. 2002. Suppression of autoimmune diabetes by viral IL-10 gene transfer. J. Immunol. 168:6479-6485.

58. Moritani, M., et al. 1996. Prevention of adoptively transferred diabetes in nonobese diabetic mice with IL-10-transduced islet-specific Th1 lymphocytes. A gene therapy model for autoimmune diabetes. J. Clin. Invest. 98:1851-1859.

59. Zipris, D., and Karnieli, E. 2002. A single treatment with IL-4 via retrovirally transduced lymphocytes partially protects against diabetes in BioBreeding (BB) rats. JOP. 3:76-82.

60. Hayashi, T., Yasutomi, Y., Hasegawa, K., Sasaki, Y., and Onodera, T. 2003. Interleukin-4-expressing plasmid DNA inhibits reovirus type-2-triggered autoimmune insulitis in DBA/1 J suckling mice. Int. J. Exp. Pathol. 84:101-106.

61. Horiki, M., et al. 2003. High-level expression of interleukin-4 following electroporation-mediated gene transfer accelerates Type 1 diabetes in NOD mice. J. Autoimmun. 20:111-117.

62. Feili-Hariri, M., et al. 2003. Dendritic cells transduced to express interleukin-4 prevent diabetes in nonobese diabetic mice with advanced insulitis. Hum. Gene Ther. 14:13-23.

63. Lee, M., Ko, K.S., Oh, S., and Kim, S.W. 2003. Prevention of autoimmune insulitis by delivery of a chimeric plasmid encoding interleukin-4 and interleukin-10. J. Control. Release. 88:333-342.

64. Piccirillo, C.A., Chang, Y., and Prud'homme, G.J. 1998. TGF- $\beta 1$ somatic gene therapy prevents autoimmune disease in nonobese diabetic mice. J. Immunol. 161:3950-3956.

65. Chang, Y., and Prud'homme, G.J. 1999. Intramuscular administration of expression plasmids encoding interferon-gamma receptor/IgG1 or IL-4/IgG1 chimeric proteins protects from autoimmunity. J. Gene Med. 1:415-423.

66. Prud'homme, G.J., and Chang, Y. 1999. Prevention of autoimmune diabetes by intramuscular gene therapy with a nonviral vector encoding an interferon-gamma receptor/IgG1 fusion protein. Gene Ther. 6:771-777.

67. Lu, L., et al. 1999. Transduction of dendritic cells with adenoviral vectors encoding CTLA4-Ig markedly reduces their allostimulatory activity [abstract]. Transplant. Proc. 31:797.

68. Lu, L., et al. 1999. Genetic engineering of dendritic cells to express immunosuppressive molecules (viral IL-10, TGF-beta, and CTLA4Ig). J. Leukoc. Biol. 66:293-296.

69. Daaboul, J., and Schatz, D. 2003. Overview of prevention and intervention trials for type 1 diabetes. Rev. Endocr. Metab. Disord. 4:317-323.

70. Bagley, J., and Iacomini, J. 2003. Gene therapy progress and prospects: gene therapy in organ transplantation. Gene Ther. 10:605-611.

71. White, S.A., Nicholson, M.L., and Hering, B.J. 2000. Can islet cell transplantation treat diabetes? BMJ. 321:651-652.

72. Shapiro, J., et al. 2000. Islet transplantation in seven patients with type-1 diabetes mellitus using a glucocorticoid-free immunosuppressive regimen. N. Engl. J. Med. 343:230-238.

73. Ryan, E.A., et al. 2001. Clinical outcomes and insulin secretion after islet transplantation with the Edmonton protocol. Diabetes. 50:710-719.

74. Sutherland, D.E., et al. 1984. Twin-to-twin pancreas transplantation: reversal and reenactment of the pathogenesis of type I diabetes. Trans. Assoc. Am. Physicians. 97:80-87.

75. Riviere, I., Brose, K., and Mulligan, R.C. 1998. Effects of retroviral vector design on expression of human adenosine deaminase in murine marrow transplant recipients engrafted with genetically modified cells. Proc. Natl. Acad. Sci. U. S. A. 92:6733-6737.

76. Dialynas, D.P., et al. 1984. Characterization of the murine T cell surface molecule designated L3T4, identified by monoclonal antibody GK1.5: similarity of L3T4 to the human Leu 3/T4 molecule. J. Immunol. 131:2445-2451.

77. Shen, F.-W. 1983. Monoclonal antibodies to mouse lymphocyte differentiation alloantigens. In Monoclonal antibodies and T-cell bybridomas. G.J. Hammerling, U. Hammerling, and J.F. Kearney, editors. Elsevier North-Holland. Amsterdam, The Netherlands. 25-31. 